\title{
Breeding behaviour of Dubois's leaping frog Indirana duboisi (Anura: Ranixalidae)
}

\author{
MADHUSHRI MUDKE ${ }^{1,2^{*}}$ \& PAVAN KUMAR THUNGA ${ }^{1}$ \\ ${ }^{1}$ Suri Sehgal Center for Biodiversity and Conservation, Ashoka Trust for Research in Ecology and the Environment (ATREE), \\ Royal Enclave, Jakkur Post, Bangalore 560064, India \\ ${ }^{2}$ Manipal Academy of Higher Education, Manipal 576104, India \\ *Corresponding author e-mail: madhushri.m@atree.org
}

Thers here is still much to learn about the reproductive behaviour of amphibians that lay their eggs terrestrially. Some species show elaborate forms of parental care, in particular oviposition site fidelity and the construction of nests that act as oviposition sites (Wells, 2007). In this context, a nest is defined as any modifications or clearing of habitat or vegetation for egg laying (Peter \& Reid 2010). Frogs of the genus Indirana are endemic to India (Modak et al., 2018) and may either attach their eggs to tree bark, place them within rocky crevices (Gaitonde \& Giri, 2014) or lay them in nests prepared by males. These frogs show inguinal amplexus (male grasping the waist of the female) and at least in the case of Indirana leithii have semi-aquatic tadpoles that live on rocks and feed on algae and diatoms using their oral apparatus that develops immediately after hatching (Modak et al., 2018). There is also a report of possible egg clutch guarding in Indirana semipalmata (Tapley et al., 2011).

Dubois's leaping frog Indirana duboisi Dahanukar, Modak, Krutha, Nameer, Padhye, and Molur, 2016 was erected as a new species following taxonomic revisions of the Ranixalidae (Dahanukar et al., 2016; Garg \& Biju, 2016). In 2019, the species was recorded for the first time from the laterite plateaus of Manipal (Karnataka State) that adjoin the Western Ghats (Mudke et al., 2020). The site where it was observed $\left(13^{\circ} 20^{\prime} 27.24^{\prime \prime} \mathrm{N} 74^{\circ} 47^{\prime} 13.56^{\prime \prime} \mathrm{E}\right)$ is at an altitude of $80 \mathrm{~m}$ a.s.l. and has an average rainfall of $3700 \mathrm{~mm}$ during the south-west monsoon (Seshadri et al., 2016). This site is close $(8.7 \mathrm{~km})$ to the sea and at a lower altitude than the earlier records of Indirana spp. (Dahanurkar et al., 2016; Garg \& Biju, 2016). This new record lies outside the popular Western Ghats boundary on a plateau that is considered as a 'wasteland'.

This new locality record of $I$. duboisi offered an opportunity to observe the habitat in which breeding occurs and the capacity of the species to modify its micro-habitat for the purpose of breeding. In July to August 2019, the peak months of the monsoon, a total of 16 surveys ( 2 surveys per week) were made as a part of our larger project on impacts of urbanisation to observe the frogs in their breeding habitat. The surveys were at night between $19.00 \mathrm{~h}$ and $21.00 \mathrm{~h}$ and in that period the frogs were observed for a total of about 60 minutes. Temperature and humidity was measured using a portable thermohygrometer (Hanna Instruments, HI9564). The dimensions of a single nesting site was measured using a flexible metal tape measure and to avoid disturbing the frog tending the nest, measurements were only done immediately after the end of monsoons when the male had dispersed.

\section{Confirmation of identity}

Ranixalid frog species tend to be cryptic which in the past has resulted in misidentifications (Garg \& Biju, 2016). We determined the species identity based on DNA extraction from 2 tadpole tail tips taken from the study site where nest building was observed. During the field surveys, wet rocks were scanned under torch light to find semi-aquatic tadpoles. A clean pair of powder free, nitrile gloves was worn for tadpole handling. Each tadpole was placed on a sterile, wet Petri dish and approximately $2.5 \mathrm{~mm}$ tail-tips were removed using a sterile scalpel and separate blades for each individual (Clarke et al., 2019). At the end of the process we observed the tadpoles for 10 minutes and recorded no mortality or distress. Tail tips were stored in $90 \%$ ethanol and transported to the molecular genetics lab in Ashoka Trust for Research in Ecology and the Environment (ATREE). Total genomic DNA was extracted using Qiagen DNeasy Blood and Tissue kit following the manufacturer's protocol. The mitochondrial $16 \mathrm{~S}$ rRNA gene was chosen for species identification based on earlier studies (Biju et al., 2014). PCR amplification was done using two primers $16 \mathrm{sF}$ (5' CGCCTGTTTATCAAAAACAT 3') and 16SR (5' CCGGTCTGAACTCAGATCACGT 3') (Palumbi, 1991). The PCR was performed following the protocol laid out in Biju et al., (2014) and Gururaja et al., (2014). The amplified PCR products were purified and sequenced at Barcode Biosciences, Pvt. Ltd. (Bangalore, India) using $A B I$ 3730xl DNA sequencer. Each DNA sequence was trimmed to clear the initial and concluding low quality base pairs and aligned in MEGA 10.1.6. Multiple forward sequences thus obtained were used to query the NCBI BLAST database. Our sequences showed $100 \%$ identity with $I$. duboisi accession KX641817 collected from Karnataka, Kerekatte (13 ${ }^{\circ} 19^{\prime} 21.9^{\prime \prime}$ $\mathrm{N}, 75^{\circ} 8^{\prime} 45.6^{\prime \prime}$ E) (Dahanukar et al., 2016). We deposited the study sequences in GenBank under accession numbers MN952996 and MN952997.

\section{Breeding habitat}

Adult males were visibly smaller than females and were seen and heard vocalising during the field surveys (Fig. 1). We observed that $I$. duboisi tadpoles and adults were associated 
with moist, laterite rocks and the ephemeral vegetation that grows on the rocks during peak monsoon months of July to August (Figs. 2A\&B \& 3A). On almost all laterite rocks the semi-aquatic tadpoles were seen feeding on the algae that grew on them, in a similar manner to I. leithii (Modak et al., 2018). During the survey period (19.00h to $21.00 \mathrm{~h}$ ) at the study site the mean temperature was $26.6{ }^{\circ} \mathrm{C}$ and relative humidity $90 \%$.
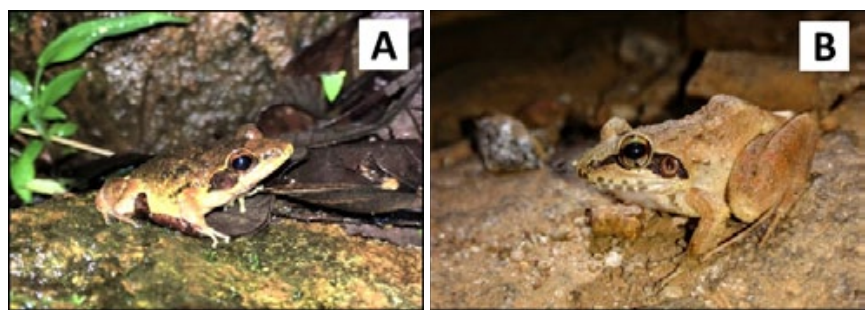

Figure 1. Adult I. duboisi - A. Male (SVL = $32 \mathrm{~mm})$, and B. Female (SVL $=45 \mathrm{~mm}$ )
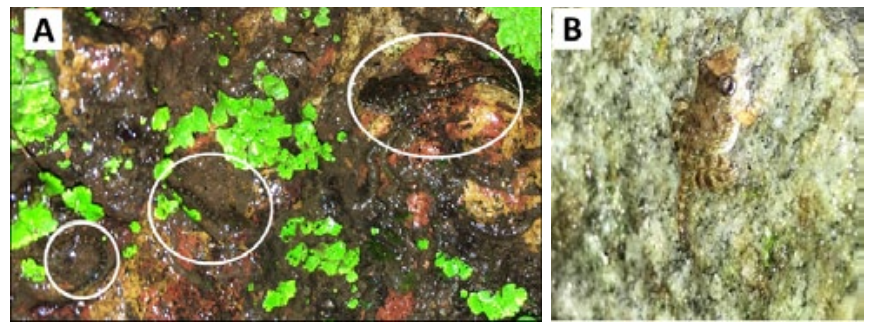

Figure 2. Tadpoles of $I$. duboisi - A. Three tadpoles at different developmental stages (indicated by white ellipses) on moist rocks interspersed with ephemeral vegetation, B. Nearly fully metamorphosed froglet on a moist rock

\section{Nest building and nest attendance}

A single male was observed creating a nest in an existing cavity within the laterite rock (Fig. 3B). It used its hind limbs to clear fallen leaves, saturated mud, ephemeral vegetation and other debris from the cavity. The nest cavity, which can be seen in a video (YouTube, 2020), had an opening measuring roughly $7.5 \mathrm{~cm}$ by $4.5 \mathrm{~cm}$ and a depth of $3.5 \mathrm{~cm}$. There was a stream of water dripping into the cavity, creating a puddle of about $4 \mathrm{~cm}$ diameter, and an outflow (Fig. 3C). These characteristics appear to help maintain the humidity, temperature and availability of water at the oviposition site. The male continued to attend this cavity in the monsoon months and made advertisement calls that can be heard in the video. Within the nest there were impressions in the mud, visible in the video and the photographs, from what may have been a previous egg clutch (Fig. 3C). It seems possible that the nest was being used for successive egg clutches. We did not actually observe any eggs in the nest despite the presence of the male frog, suggesting these may have been predated, that the male was never favoured by a female, or that egg laying and hatching occurred in an interval between our surveys. The last conjecture is suggested as a possibility since Tapley et al. (2011) observed that the eggs of I. semipalmata hatched within only four to five days. In the last week of August 2019, approaching the end of monsoon season, the nest site was abandoned by the male and debris, leaves and vegetation had accumulated within it (Fig. 3D).

The lateritic plateaus are currently categorised as 'wastelands' by the Ministry of Rural Development and National Remote Sensing Agency, (2010). Yet they are home to unique and interesting endemic frog species. The
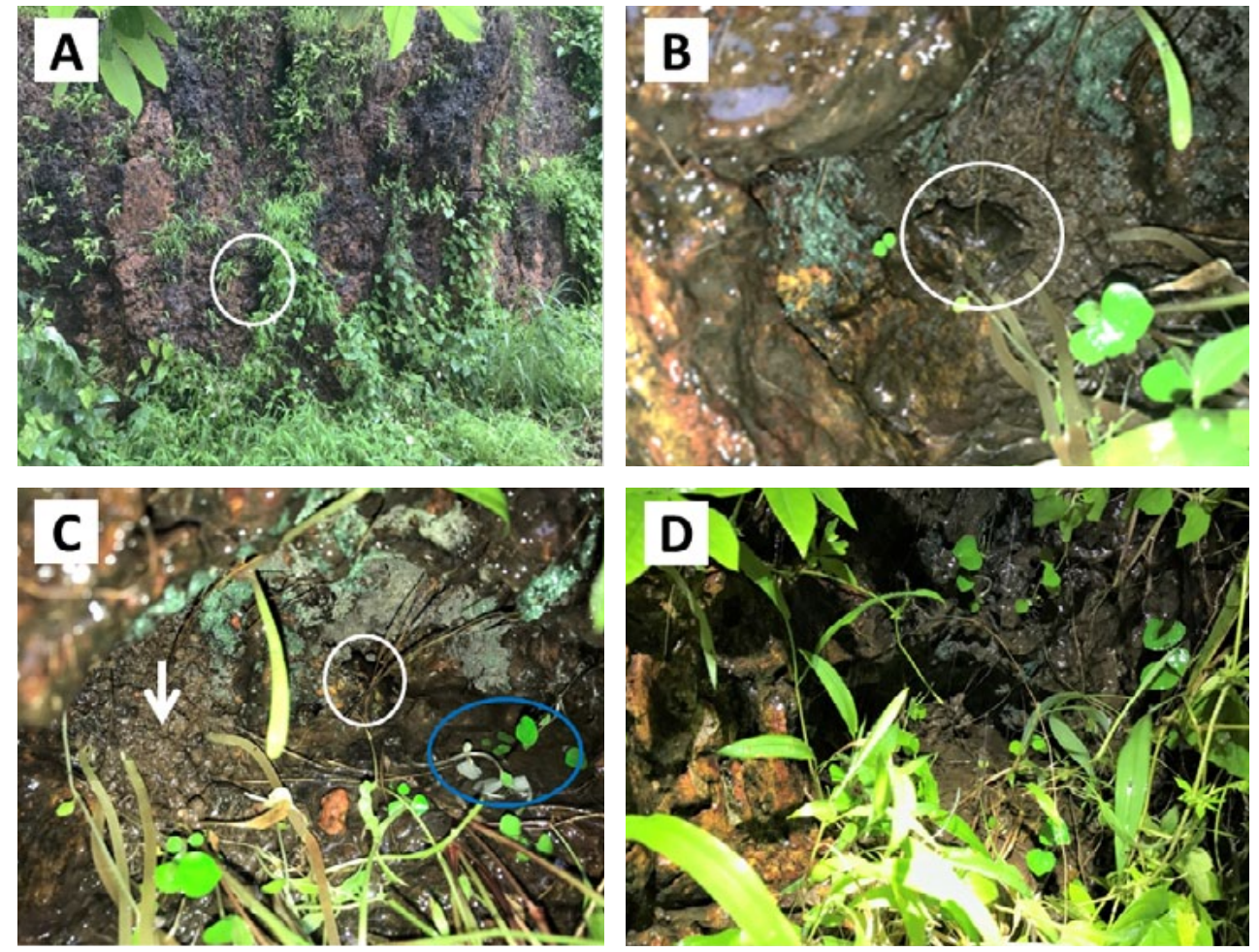

Figure 3. Habitat for nest construction by I. duboisi - A. Habitat containing a nest consisting of wet rocks and ephemeral vegetation (nest position indicated by white ellipse), B. Close up of the nest attended by a male (in white ellipse), C. The nest with the male (white ellipse), potential egg clutch impressions (white arrow) and puddle of water (blue ellipse), D. The same cavity showing accumulation of debris and vegetation after the male had abandoned it 
observations reported here show that there are still important secrets to be uncovered in the biology and behavior of India's native species and that the plateaus can serve as effective ecological study sites and conservation areas if managed with biodiversity concerns in mind.

\section{ACKNOWLEDGEMENTS}

We are grateful to our mentors Dr Gururaja KV, Dr Aravind NA and Benjamin Tapley for their continuous support and advice, Dr Ravikanth for lab facilities, Archit Kejriwal for overseeing the draft manuscript and ATREE internal funds for making sequencing and DNA extraction possible. We are also grateful to two anonymous reviewers for constructive comments.

\section{REFERENCES}

Biju, S.D., Garg, S., Gururaja, K.V., Shouche, Y. \& Walujkar, S.A. (2014). DNA barcoding reveals unprecedented diversity in dancing frogs of India (Micrixalidae, Micrixalus): a taxonomic revision with description of 14 new species. Ceylon Journal of Science (Biological Sciences) 43: 37123.

Clarke, G.S., Phillips, B.L. \& Shine, R. (2019). Clipping the tail fin enables cohort identification of small anuran tadpoles. Copeia 107: 71-77.

Dahanukar, N., Modak, N., Krutha, K., Nameer, P.O., Padhye, A.D. \& Molur, S. (2016). Leaping frogs (Anura: Ranixalidae) of the Western Ghats of India: An integrated taxonomic review. Journal of Threatened Taxa 8: 9221-9288.

Gaitonde, N. \& Giri, V. (2014). Primitive breeding in an ancient Indian frog genus Indirana. Current Science 107: 109-112.

Garg, S. \& Biju, S.D. (2016). Molecular and morphological study of leaping frogs (Anura, Ranixalidae) with description of two new species. PloS one 11. e0166326. doi: 10.1371/journal.pone.0166326

Gururaja, K.V., Dinesh, K.P., Priti, H. \& Ravikanth, G. (2014). Mud-packing frog: a novel breeding behaviour and parental care in a stream dwelling new species of Nyctibatrachus (Amphibia, Anura, Nyctibatrachidae). Zootaxa 3796: 33-61.
Ministry of Rural Development and National Remote Sensing Agency (2010). Wastelands atlas of India. National Remote Sensing Agency, Dept. of space, Govt. of India, Hyderabad, 74 pp. http://dolr.gov.in/sites/default/files/wateland\%20 Introduction-\%20forword\%20.pdf. Accessed March 2019.

Modak, N., Chunekar, H. \& Padhye, A. (2018). Life History of Western Ghats endemic and threatened Anuran Matheran leaping frog (Indirana leithii) with notes on its feeding preferences. Journal of Natural History 52: 17451761.

Mudke, M., Gururaja, K.V., Aravind, N. \& Singal. R., (2020). Annotated list of anurans from the lateritic plateau of western India with notes on malformations. Check List 16: 685-698. doi: 10.15560/16.3.685

Palumbi, S.R., Martin, A.P., Romano, S.L., McMillan, W.O., Stice, L., Grabowski, G. \& MacMillan, W.O. (2002). The Simple Fool's Guide to PCR, version 2.0. Dept. of Zoology, University of Hawaii, Honolulu, 45 pp.

Peter, W.C. \& Reid, N.H. (2010). Egg mass and nest counts. In: Amphibian Ecology and Conservation, 143-166 pp. Dodd, C.K., Jr. (Ed.). New York: Oxford University Press Inc.

Roelants, K., Jiang, J. \& Bossuyt, F. (2004). Endemic ranid (Amphibia: Anura) genera in southern mountain ranges of the Indian subcontinent represent ancient frog lineages: evidence from molecular data. Molecular Phylogenetics and Evolution 31: 730-740.

Seshadri, K.S., Singal, R., Priti, H., Ravikanth, G., Vidisha, M.K., Saurabh, S. \& Gururaja K.V. (2016). Microhyla laterite sp. nov., a new species of Microhyla Tschudi, 1838 (Amphibia: Anura: Microhylidae) from a laterite rock formation in South West India. PloS ONE 11: e0149727. doi:10.1371/ journal.pone.0149727.

Tapley, B.T., Purushotham, C.B. \& Girgin, S. (2011). Indirana semipalmata (brown leaping frog) reproduction. Herpetological Review 42: 87-88.

Wells, K.D. (2007). Mating Systems and Sexual Selection in Anurans.In:TheEcology\&BehaviorofAmphibians.338-402 pp. Chicago and London: The University of Chicago Press.

YouTube (2020). Dubois's leaping frog Indirana duboisi. https://www.youtube.com/watch?v=FMsOE4SDDOo\&fe ature=youtu.be

Accepted: 28 May 2020 